\title{
Brief Analysis on the Aging of Traction Transformer Insulation YanHong Guo ${ }^{1, a}$ \\ ${ }^{1}$ School of Liaoning Railway Vocational and Technical College, Jinzhou, 121000, China aguo321ggg@126.com
}

Keywords: Electrified railway Electrified; Traction transformer; Load curve; Solid insulated

\begin{abstract}
In the power supply system of electrified railway, traction transformer is an important part and its running state plays an important role on the safety of railway operation. In this paper, we will analyze the transformer load curve, simulates the change of the temperature rise and discuss the influence of temperature on the transformer solid insulation under load condition.
\end{abstract}

\section{Introduction}

China's power supply system of electrified railway uses single-phase power frequency ac system and electric locomotive traction load is actually the load of traction transformer, since it is beyond the provisions of GB/T15164 94, the traction transformer is more likely to breakdown compared with the ordinary power transformer. Operating experience shows that: we must have a correct understanding and treatment of the transformer's fault and damage in order to improve the operation reliability, otherwise failure and damage will happen frequently and the same fault will be repeated. Therefore, analyzing the aging of traction transformer insulation will be of great importance on the improving of electricity quality and railway transportation safety, particularly under the premise that railway is developing towards high-speed passenger transport and more loading cargo transport.

\section{The load characteristics of traction transformer}

The variance of traction load in different circumstances has led to significant difference in traction transformer load and ordinary transformer load which are shown under: the track transformer when loaded has single-phase load、 varying load track circuit 、 higher harmonic, etc. Traction transformer will transfer electric power from the three-phased power system to the two separately loaded overhead contact system and provide electric power respectively to the ascending and descending trains. The single phased load shall be the same ideally but usually varies in most state.

Statistics shows that the rate of traction empty load in one lined electrified railway is $40 \%$ $50 \%$, and the load changes more frequently, which will inevitably cause the imbalance in three-phased power system and voltage fluctuation. Traction transformer will change and transfer the electricity from $110 \mathrm{kV}$ (or $220 \mathrm{kV}$ ) three-phase power system into the two $27.5 \mathrm{kV}$ overhead contact system. Given into consideration the line loss $10 \%$, the rated voltage of overhead contact system is $25 \mathrm{kv}$, but the actual locomotive working voltage is frequently between 22-27.5 KV, so when the train passes by, instantaneous short circuit will happen (normally 70 times per year) due to flashover of the conductive support insulator, during which the electric current is 6-10 times of the rated curren. Therefore, the traction transformer shall have enough anti-short-circuit strength and impact resistance ability.

\section{Winding temperature rise simulation and calculation under typical load.}

According to the characteristics of the traction power supply system, railway departments have proposed idea of typical load curve (as shown in figure 1) on the basis of extensive investigation and numerous tests. Typical load curve reflects the load characteristics of the traction transformer. But the characteristics of the traction power supply system determine that the transformer load characteristics are ever changing, and there are sometimes still differences with the actual load 
curve. In this paper, we will simulate and calculate the temperature of traction transformers according to the typical load curve shown in figure 1, and hence to make tests and research.

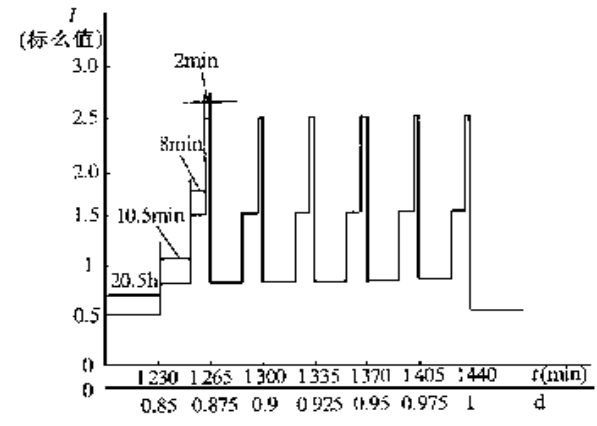

(a)

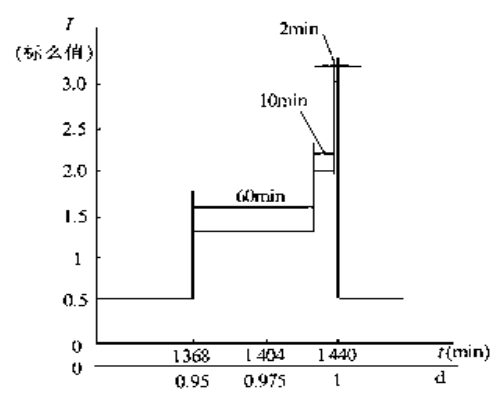

(b)

Fig.1 Typical load curve

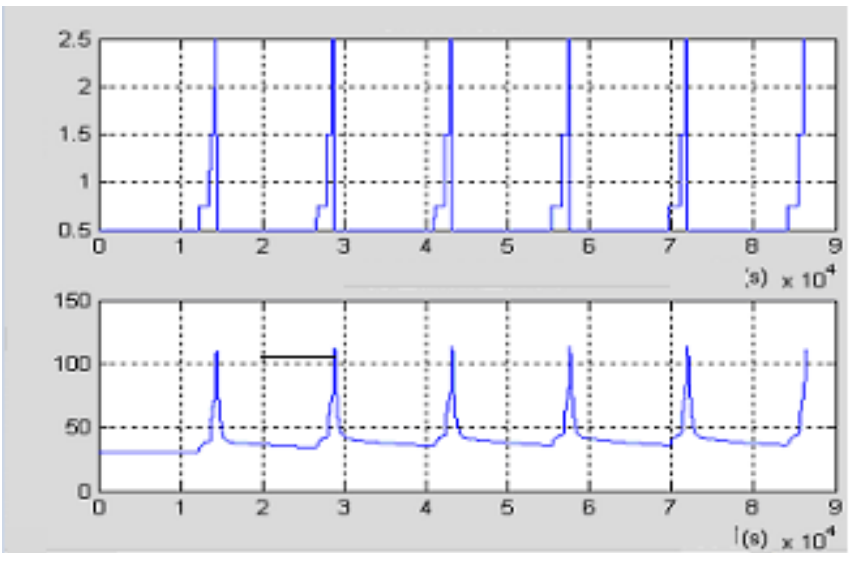

Fig.2 Traction load and temperature change

According to the calculation method of transformer winding hot spot temperature rise in the IEC354 guidelines and simulated with matlab 6.5, the results are shown in figure 2.

\section{Thermal aging effects on traction transformer}

Thermal aging effects on traction transformer are mainly caused by temperature, humidity, oxidation and degraded materials decomposed from oil. The speed is mainly decided by temperature, the higher the working temperature of the insulating material, the faster the chemical reaction (mainly oxidation), and the faster the loss of the mechanical and electrical strength of the insulation, the shorter the service life of the transformer.

The transient temperature calculation:

Transient temperature rise of the transformer's top oil.

In any load cases $K_{i}$, the top oil temperature rise $\Delta T_{T O(i)}(t)$ after time $t$ is:

$$
\Delta T_{T o(i)}(t)=\Delta T_{T o(i-1)}+\left(\Delta T_{T o(i)}-\Delta T_{T o(i-1)}\right)\left(1-e^{\frac{-t}{\tau_{0}}}\right)
$$

in which $\Delta T_{T O(i)}$ load $K_{i}$ Stable oil temperature rise under;

$\Delta T_{T O(i-1)}$ load $K_{i-1}$ ends and the top oil temperature rises, which is the initial temperature rise when load $K_{i}$ works. $\tau_{0} \longrightarrow$ oil time constant.

Transient temperature when transformer reaches the hottest point.

In any load cases $K_{i}$, the top oil temperature rise $T_{H S(i)}(t)$ after time $t$ is:

$$
T_{H S(i)}(t)=T_{A}+\Delta T_{T O(i)}(t)+\left(\Delta T_{H S(i)}-\Delta T_{H S(i-1)}\right)\left(1-e^{\frac{-t}{\tau_{0}}}\right)
$$

as time constant of the winding is very small, and even overloaded in a short period of time, it has 
very little influence on the hot-spot temperature,so he time constant can be approximately treated as zero in the process of calculation. So the equation above can be rewritten into:

$$
T_{H S(i)}(t)=T_{A}+T_{T O(i)}(t)+H g_{r} K_{i}^{2 m}
$$

We can now calculate the winding temperature of the traction transformer from equations 1-3 and load curve and here we get the results in table 1 and table 2.

Table 1 Winding hot-spot temperature and temperature rise (based on 1-a curve)

\begin{tabular}{|c|c|c|c|c|}
\hline Load coefficient & 0.5 & 0.75 & 1.5 & 2.5 \\
\hline $\begin{array}{l}\text { Winding hottest -point } \\
\text { temperature rise (k) }\end{array}$ & 26.8 & 33.2 & 56.9 & 98.4 \\
$\begin{array}{c}\text { Winding hottest -point } \\
\text { temperature (k) }\end{array}$ & 46.8 & 53.2 & 76.9 & 118.4 \\
\hline
\end{tabular}

Table 2 Winding hot-spot temperature and temperature rise (based on 1-b curve)

\begin{tabular}{|l|c|c|c|c|}
\hline \multicolumn{1}{|c|}{ Load coefficient } & 0.5 & 1.25 & 2.0 & 3.0 \\
\hline $\begin{array}{l}\text { Winding hottest -point } \\
\text { temperature rise (k) }\end{array}$ & 26.8 & 56.5 & 87.8 & 135.6 \\
$\begin{array}{l}\text { Winding hottest -point } \\
\text { temperature (k) }\end{array}$ & 46.8 & 76.5 & 107.8 & 155.6 \\
\hline
\end{tabular}

\section{Thermal aging effects on insulation paper}

Thermal aging is mainly caused by heat during the operation of the traction transformers and the winding hottest-spot temperature which is caused by transformer loss plays most important role. Oil is heated in air and oxidized and aged with catalyst of metals like iron. The macromolecules of the insulation paper will be cracked and the average degree of polymerization will be lowered. $\mathrm{CO}, \mathrm{CO}_{2}$ are the aging products of the fiber materials and IEC599 suggests the ratio of $\mathrm{CO}, \mathrm{CO}_{2}$ can be the basis for analysis which states that when $\mathrm{CO} / \mathrm{CO}_{2}>0.33$ or $\mathrm{CO} / \mathrm{CO}_{2}<0.09$, there will be possibilities that the fiber insulation is decomposed, but it has many limitations in use, which needs further analysis. When the fiber is heated, affected with damp or oxidized, furfural will be produced. Concentration of furfural in oil can be used to judge the aging of the transformer insulation paper .It is generally believed that, when oil concentration is $0.05 \mathrm{mg} / \mathrm{L}$, the transformer is in its middle life of insulation; when furfural concentration reaches $1 \mathrm{ml} / \mathrm{L}-2 \mathrm{mg} / \mathrm{L}$, the transformer insulation degradation is serious; but when above $3.5 \mathrm{mg} / \mathrm{L}$,the life of the transformer shall be terminated. There is corresponding relations between furfural content and polymerization degree and the formula shows below:

$$
\log (\text { Furan })=1.51-0.0035 D P
$$

In which : Furan_—furfural content, mg/L ; DP_—polymerization degree

In order to have a better understanding of the aging of the traction transformer insulation, many scholars have made experiments and studies on the transformer solid insulation and basically can be divided into the following two models.

The oil paper insulation is heated at $140{ }^{\circ} \mathrm{C}, 150{ }^{\circ} \mathrm{C}, 150{ }^{\circ} \mathrm{C}$ within different time period and mainly check the furfural content of insulating paper to decide the aging state of the insulating paper based on the relation formula with the degree of polymerization.

Aging test will be carried out from $70^{\circ} \mathrm{C}$, with $10^{\circ} \mathrm{C}$ added every day , until $180{ }^{\circ} \mathrm{C}$. When it is heated after 24 hours in each temperature, measure the gas composition, content and furfural content, judge the aging degree of the insulating paper based on the furfural content after heating through the relation between CO and DP and further find out the effects of heat aging on insulation when loaded.

The test data is shown in figure 3 : 

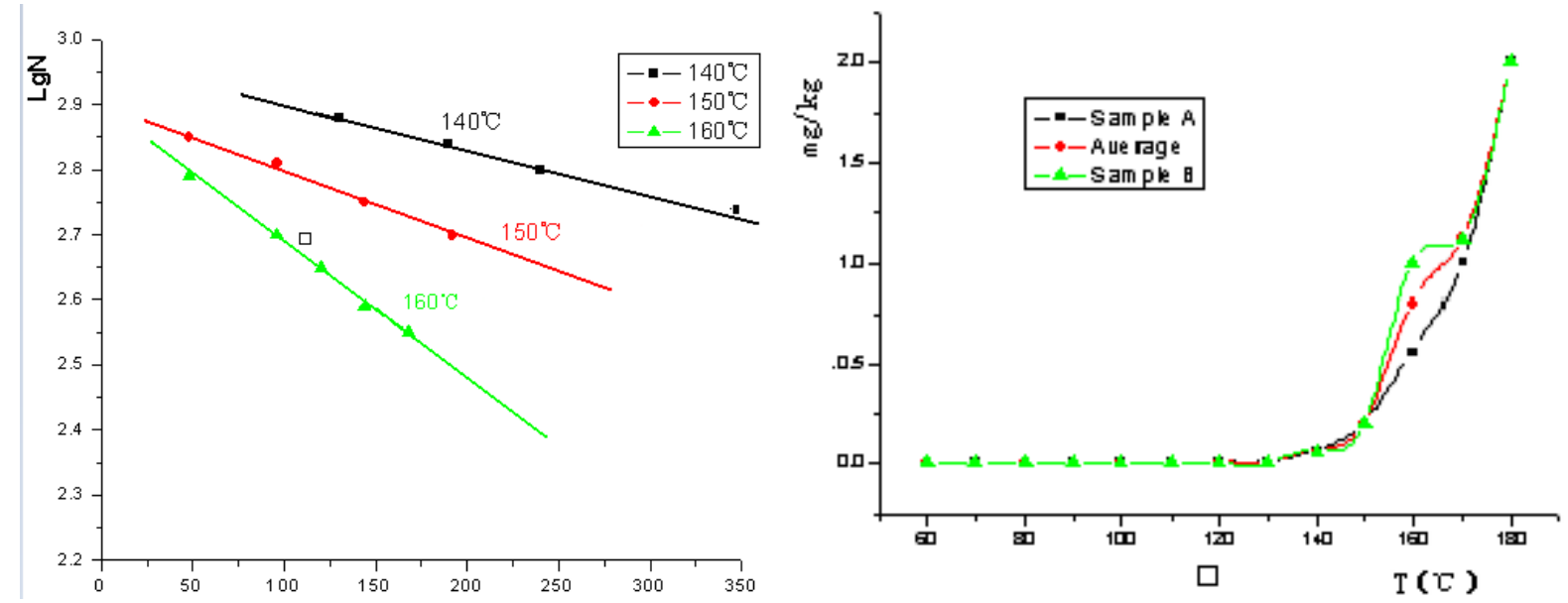

Fig. 3 Temperature effects on insulating paper

The main insulation materials used in transformers are oil and paper. Transformers will be affected by electric field, moisture, temperature and mechanical force during long time operation and will be degraded and eventually malfunctioned. As a result, Real-time detection and diagnosis become urgent problems needs to be discussed and resolved.

\section{Conclusion}

According to the results of the insulating oil paper heating test made when simulating the running state of traction transformers, traction load has great influence on the insulating paper of the transformers. From the case studies we see factors that have effects on the aging of the traction transformer insulation can be from construction, installation, and operation and others. Therefore, traction transformer real-time monitoring technology shall be strengthened for the timely monitoring of the insulation state to find out potential faults and this is of great significance for the safety of electrified railway transportation.

\section{References}

[1] Guo mansheng, the characteristics and development of the traction transformer [J]. electrician technology magazine, 2001(1).

[2] Zhang bo, traction transformer fault analysis [J]. transformer, (1996).

[3] Michel Duval, New Techniques for Dissolved Gas-in-Oil Analysis[J]. IEEE Electrical Insulation Magazine, 2003, 19 (2).

[4] Zhou lijun, The traction transformer on-line monitoring system based on DGA technology research [D]. master's thesis of southwest jiaotong university, 2004. 